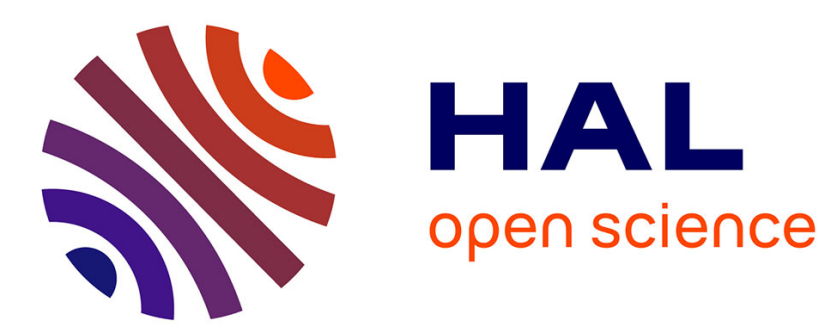

\title{
Analysis of Mixed Reality Tools for Learning Math in Primary and Secondary School
}

\author{
Sofiane Touel, Iza Marfisi-Schottman, Sébastien George
}

\section{To cite this version:}

Sofiane Touel, Iza Marfisi-Schottman, Sébastien George. Analysis of Mixed Reality Tools for Learning Math in Primary and Secondary School. International Conference on Games and Learning Alliance, Dec 2020, Laval (virtual), France. pp.112-121, 10.1007/978-3-030-63464-3_11 . hal-03143836

\section{HAL Id: hal-03143836 https://hal.science/hal-03143836}

Submitted on 17 Feb 2021

HAL is a multi-disciplinary open access archive for the deposit and dissemination of scientific research documents, whether they are published or not. The documents may come from teaching and research institutions in France or abroad, or from public or private research centers.
L'archive ouverte pluridisciplinaire HAL, est destinée au dépôt et à la diffusion de documents scientifiques de niveau recherche, publiés ou non, émanant des établissements d'enseignement et de recherche français ou étrangers, des laboratoires publics ou privés. 


\title{
Analysis of Mixed Reality Tools for Learning Math in Primary and Secondary School
}

\author{
Sofiane TOUEL ${ }^{1}$, Iza MARFISI-SCHOTTMAN ${ }^{2}$ and Sébastien GEORGE $^{2}$ \\ ${ }^{1}$ Plaisir Maths Lab, 75011 Paris, France, Sofiiianos@outlook.com \\ ${ }^{2}$ Le Mans Université, EA 4023, LIUM, 72085 Le Mans, France \\ \{iza.marfisi, sebastien.george\}@univ-lemans.fr
}

\begin{abstract}
In our study, we provide a state of the art on Mixed Reality (MR) learning tools for teaching math in primary and secondary school. Through a detailed analysis of eight representative applications, we provide an overview of the MR applications currently used, their educational objectives, the augmentations and interactions they offer, the technologies they use, their advantages and their limitations. We conclude by identifying several remaining challenges that need to be addressed in order to benefit from the full educational potential of MR for teaching math in schools.
\end{abstract}

Keywords: Learning, augmented reality, mixed reality, math, serious game.

\section{$1 \quad$ Mixed Reality to Help Children Learn}

Teaching methods have evolved a lot in the recent decades. The use of digital tools has become widespread because they are essential in modern professional and non-professional life, but also because they have many educational benefits. Among these digital innovations, we will focus on Mixed Reality (MR).

As defined by Drascic and Milgram [1], "MR refers to the incorporation of virtual computer graphics objects into a real three-dimensional scene, or alternatively the inclusion of real world elements into a virtual environment. The former case is generally referred to as Augmented Reality (AR), and the latter as Augmented Virtuality." The augmentations are displayed on a screen, in glasses or directly on real objects using a video projector. It is possible to interact with these augmentations.

The educational potential of MR comes from several factors. First, the manipulation of real objects has an impact on embodied cognition and would allow to significantly reduce mental load [2]. Object manipulation also motivates learners and encourages them to carry out their activities [3]. In addition, Chandler and Tricot's study [4] demonstrates the positive impact of physical activity that accompanies this object manipulation, especially for young children. Physical movement seems to be especially relevant for mathematical cognition. It is through the explanation of mathematical concepts that one can notice different types of gestures (pointing, representation and metaphorical gestures) which make it possible to externalize information and improve 
memory management [5]. Finally, MR makes it possible to create multimodal (visuohaptic) activities, which have a superior pedagogical potential over unimodal (visual) activities for children [6]. MR allows, for example, displaying different types of contextualized information directly on physical objects (e.g. 3D animated model of the solar system, organ names). MR can also give students more autonomy by displaying information to guide them (e.g. contextual information or step-by-step guide on the actions to be performed) or even validate the activities once they have been completed (e.g. validation of the objects position).

Some studies also show that students using AR have better understanding of the course and memorization, compared to those using only books [7]. In addition, MR improves the involvement and engagement of learners in learning tasks [8] and is confirmed by Kun-Hung Cheng's study of 267 middle school students [9]. However, these previous studies also revealed some negative points. Some students think MR is responsible for reducing imagination and obstructing their reading skills. In addition, the equipment used can be expensive but also complicate the activities [10]. This equipment can also be tedious to set up for teachers but also to use for students $(e . g$. wearing glasses for a long time).

Despite the undeniable potential of MR, its integration into schools therefore raises a certain number of questions related to the type of activities and equipment that should be used to maximize its educational potential without constraining teachers and students. In the rest of this article, we focus on MR for math. As we will present, this is an area which has a strong impact on other scientific fields and which could particularly benefit from the advantages of MR.

\subsection{Learning Math with Mixed Reality}

At school, all subjects are important, but math represents the knowledge from which most other sciences derive. According to the study of Watts et al. [11], the skills of children aged four to five would predict their scientific skills in adolescence. Another study [12] shows that succeeding in math generally implies future success in other fields such as reading. In addition, many primary school students find science to be a masculine, elitist and consider math as a difficult subject. Using a motivating medium like MR, for learning mathematics, has a positive effect on the motivation of learners [13] and could be a good solution to avoid blockage [14]. MR interactions are also very well suited to convey notions of geometry and algebra by displaying virtual 3D shapes or showing 2D information directly on 3D figures. MR applications for math are numerous and varied by the interactions they offer (display of information, help, validation), the targeted educational objectives (e.g. additions, fractions, 3D geometry), but also by the equipment they require (e.g. tablets, projectors, markers, glasses). In this article, we offer an analysis of existing MR applications, in order to understand their different characteristics and their impact on learning. 


\section{Analysis of Mixed Reality Applications for Math}

To our knowledge, even though there are a considerable number of MR applications for learning math, there is still no state of the art on this subject. We therefore propose to analyze a representative selection of these applications. We searched on Google Scholar, which indexes the articles from the main publishers (Springer, IEEE, HAL archives ouvertes, etc.) by combining the following keywords: (teaching or learning and (augmented reality or mixed reality)) or (math or fraction or geometry), (learning or teaching) and (object manipulation or physical movement) or (digital) or (preschool or primary). This research allowed us to select about 30 scientific studies.

In this paper, we will only present eight out of these 30 studies. Given the rapid technological evolution of the RM, we only chose recent studies, published after 2015, and that offer a functional prototype. The eight applications presented bellow were also selected because they come from different countries (Asian, European, American), teach various fields of math, provide a variety of interactions and require different types of equipment. The objective of this selection is to provide a good overview of existing applications.

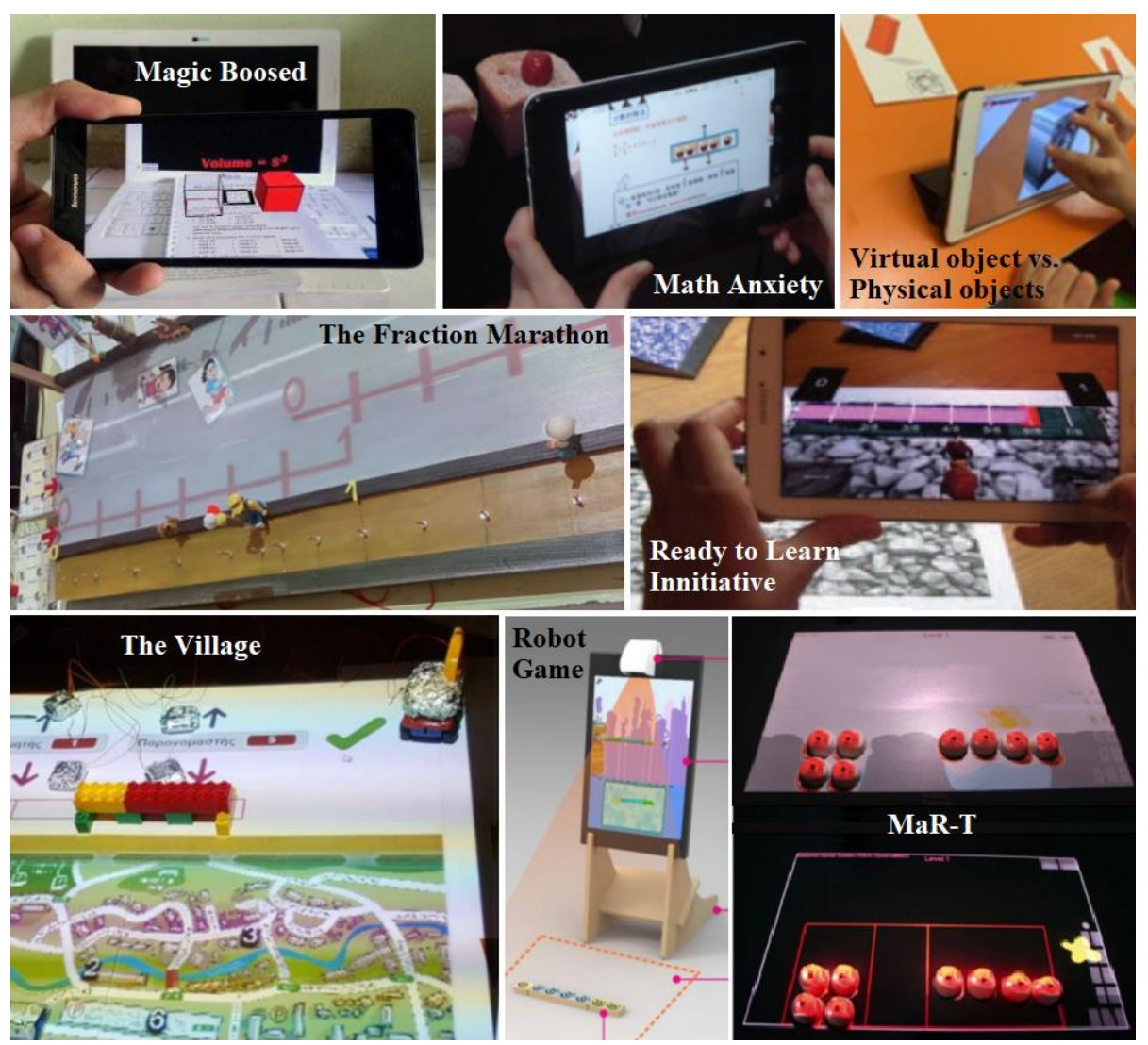

Figure 1. Eight representative Mixed Reality applications for math 
In the next section, we analyze these eight applications according to four points. First we identify the context in which they were created and their educational objectives. Then, we identify the nature of the MR interactions they offer. Thistly, we list the necessary equipment and the software used to develop the application. Finally, if the application was tested, we present the advantages and limitations identified by the authors.

\subsection{Magic Boosed}

The Magic Boosed [15] app comes from Indonesia. Its objective is to improve the spatial perception of geometric shapes for children aged 7 to 12 .

The students need to answer basic geometry questions (e.g. what is the surface of this 3D figure?). The application helps then by provides AR information (e.g. 3D objects, height, formulas). These augmentations offer no interaction.

Students are equipped with a paper exercise textbook and a smartphone with the application. The article does not provide information on the MR technology.

According to the authors, the experimentations lead with two teachers and eight students showed that the application increases the motivation and interest of the students and facilitates exchanges between them and the teacher.

\subsection{Math anxiety}

Math anxiety is a Taiwanese study [16] to reduce anxiety related to learning maths.

Eight quizzes are scattered around the classroom to review topics such as fractions and geometry. In addition to displaying $3 \mathrm{D}$ objects in $\mathrm{AR}$, the application also triggers videos when it recognizes real objects to help students answer the quizzes. These virtual items are not interactive.

The quizzed are printed out on sheets of paper. The students use tablets this the app. The application was developed with HP Reveal and Augment.

The experiment, carried out with 137 students, showed that AR app decreases anxiety in math, increases attention, motivation, confidence and student satisfaction compared to the mobile application without AR. The authors would like to add interactions and virtual 3D objects and use more efficient tools than HP Reveal and Augment as they could not customize the content and interactions according to their needs.

\subsection{Virtual object vs. Physical object}

This Turkish study compares the use of AR virtual objects and physical objects for learning geometry [17]. The objective is to teach 5 to 6 year-old children how to recognize geometric shapes, including 2D (eg triangle, square) and 3D (eg : sphere, cube).

Students have to classify cards with images of geometric shapes. They can use the $\mathrm{AR}$ app to view the $3 \mathrm{D}$ version if the geometric shapes, change their size, position, orientation and manipulate them. This app was developed with Augment.

The experimentation, lead with 72 children, showed that the application seemed to have effectively supported the learning process, and created excitement. The authors 
argue that it would be beneficial to add educational feedback to help children understand the type of each object based on the choices they make.

\subsection{The Fraction Marathon}

The Fraction marathon uses number lines to teach fractions (addition and subtractions) to 11-year-olds Greek children [18].

The game scenario features several runners interrupted in their $2 \mathrm{~km}$ race due to rain. The students must place the runners back where they stopped. Their position is given as a fraction relative to the finish point (e.g. $2 / 3$ of the finish), the position of other runners or elements of the scene. If the students make a mistake, they lose points and are prompted to click on the help button. This triggers a video with voice instructions that guides them on how to handle the lines and solve the problem._Students can measure the size between two objects by resize and moving the MR number line. They can also update the fractional unit with a physical button. The MR also automatically validates the position of the runners.

The game involves a miniature wooden stadium, a projector, a camera, a laptop, two Makey Makey boards (is an electronic invention kit that allows you to connect "everyday objects" to the computer program without any technical knowledge). The technology used to develop the game is not given in the article.

After a study lead with 28 students, the authors argue that the game immerses and amuses the students. The feedback and help mechanisms were particularly effective for empowering them. The authors also believe that it would be more effective to present the game without mentioning fractions to reduce stress at the beginning of the game. The authors also wish to enlarge the play space so that more children can play at the same time and find a less expensive solution.

\subsection{Ready To Learn Initiative}

Ready to Learn initiative [19] aims to study the potential of AR for learning certain mathematical themes (Geometry, Fraction, Counting, etc.) in the US. Among other applications, they offer an AR application for introduce fractions to children aged 6 to 9 .

Childrens place real objects on a number line and the application automatically measures the position of the object and displays it as a fraction. Students can change the denominator of the fraction, and the app automatically updates the numerator.

The app requires to print out a sheet of paper with markers and a tablet with the app. It was developed with a web version of scratch 2 .

Even if it was not tested by the students, three teachers were able to evaluate the prototype and noted that the presence of interactions with 3D objects would be likely to capture the attention of their students as well as a good potential pedagogic.

\subsection{The Village}

The village is a Greek project designed to teach fractions to elementary school children aged 6 to 12 years old [20]. 
The game scenario features a child visiting his grandparents in their partially destroyed village. Using two virtual characters, the player's goal is to repair the infrastructure of the village (eg: the pipe, the bridge represented by legos), by measuring the damaged part (in red) with the number line. Players can adjust the size, numerator and denominator of the MR digital line by manipulating screwdrivers and knobs. The game automatically detects if the damaged part of the infrastructure is correctly measured.

The game consists of a Makey Makey board, a projector, a table and accessories. The game was developed with MIT Scratch (block-based visual programming).

This game was not tested in an educational context. The authors' perspectives are to use mobile devices in order to simplify the game.

\subsection{Robot Game}

The Uruguayan robot game, aims to teach additions [21] to children aged 5 to 6.

The players must choose enough blocks (lengths from 1 to 5) to extend a robot's arm by placing physical blocks in front of the tablet so that it can reach a screw. The system provides continuous real time feedback by extending the robot's arm.

To be able to use the game, children need a tablet, a tablet holder, as well as a mirror and a wooden block set. The game was developed with the open source platform CETA, OpenCV, libgdx and TopCode libraries.

After testing the game with 19 students, the authors argue that it provides cognitive offload, increases commitment and joy and empowers students through the feedback system. Their perspectives are to use a markerless technology, improve the feedback by making it fluid and add animations and advice from the robot.

\subsection{MaR-T}

This Turkish study aims to help children aged 3 to 5 understand non-symbolic numbers and compare values [22].

The children must help Momo, a fictional character, to get home by placing objects in the designated locations to allow Momo to cross obstacles (e.g. river, ditch). Momo then asks them to point to the side where there are the most objects or to put their hand in the middle if there are as many on both sides. If the children give the correct answer they are congratulated, otherwise Momo asks questions such as "Why do you think this side has more than the other?".

This game requires a camera and a projector and was been developed with OpenCV, Royale SDK, IR image, Lottie and Bodymovin libraries.

After testing the game with ten children, the authors argue that the interactions with Momo helps children keep focused. The feedback and reward systems also seemed to help the children complete the activities. 


\section{Global Analysis}

\subsection{Variety of Educational Objectives}

The examples analyzed above show that MR can be used for learning math at all levels. For example, MR can be used for learning the basics of math such as the Robot Game and MaR-T. There are many other MR applications that teach additions and subtractions. For example, the Counting With Paula AR app [7] or the AR Flashcards Addition application [23]. The effectiveness of MR for teaching the basics of math appears to be due to its capacity to immerse students in a fun environment and arouse their curiosity [3] which leads to a better understanding and motivation [24].

AR is also well adapted to teach geometry, such as Magic Boosed, Math anxiety and Virtual object vs Physical object. There are many MR applications for this topic, certainly due to the fact MR technology improves spatial intuition of students, which is an effective way to learn geometry [25].

Finally, AR seems particularly effective for teaching fractions, which often discourage students and push them to dislike math. The use of MR, such as The Fraction Marathon, Ready To Learn Initiative or The Village, can transform this complex and unpopular matter into a fun and captivating experience.

\subsection{Analysis of Mixed Reality Interactions}

The applications analyzed above present two types of MR interactions. The first group offers very light or non-existent AR interactions, such as Ready To Learn Initiative, Virtual Object vs Physical Object and Magic Boosed. These applications only use AR to display virtual information on real objects. At best, the students can manipulate, turn and change the size of the virtual augmentations. These applications have the advantage of being easy to set up since they only require a tablet or smartphone and printed out markers on paper or cardboard.

The second group of applications offer rich MR interactions, in which we find MaR-T, The Village, The Fraction Marathon, Robot Game and Math anxiety. In addition to the AR augmentations, the manipulation and the position of the real objects have an impact on the applications. In MaR-T for example, it is the position of the cubes that triggers the next level in the game. Some of these applications also offer personalized feedback and help. Such rich interactions have undeniable advantages for different areas of learning. For example, studies in the medical field show that the presence of feedback contributes to the development of psycho-motor and cognitive skills [26]. Another study [27] shows that students appreciate this type of rich interaction, and in particular the feedback, which promotes self-regulated learning, at their own pace. However, the applications mentioned above all require specific equipment such as projectors, 3D objects, as well as space, thus making their use in a school complicated. 


\subsection{Analysis of Mixed Reality Hardware and Software}

The most common hardware to support MR applications are Smartphone and tablets. This is for example the case of Ready To Learn Initiative, Virtual Object vs Physical Object and Magic Boosed. According to a study in Switzerland, on more than 1,000 students, $78 \%$ from age 6 to 13 use mobile phones regularly and 3/4 of students aged 12 to 13 already owned one [28]. The figures for tablets are similar. The fact that the majority of children are already familiar with this equipment is an important advantage to using them in class. On the other hand, tablets or smartphones do not allow having both hands free to handle objects. In addition, some devices do not support advanced technologies such as Vuforia's Ground Plane technology, which allows placing digital content on a table [29].

The other hardware used for the MR is projectors and cameras. This is for example the case of The Village, The Fraction Marathon and Math anxiety. They have the advantage of being moderately expensive and users have their hands free to manipulate objects. In addition, projectors have a wide field of vision, and allow group work [30]. However, they take up allot a room and are complex to set up. Indeed, the projector and the tracking camera need to be calibrated and placed directly above the working area. The Robot Game is a simplified version of this setup because it uses a holder and a mirror to use the tablet's camera. It is simple to set up but offers a narrow field of vision. Finally, even though none of the applications above use this technology, it is important to cite AR glasses and headsets mostly used for professional training, due to their very high cost. These have the advantage of offering good perception of depth [31]. Their mobility is also a major asset since the devices can be transported everywhere and leave the user's hands free. However, they can cause visual fatigue and nausea.

There are several types of software to design MR applications. Teachers can use AR application editors that allow them to create AR applications without any development skills such as Augment [32] and Aurasma [33]. Thanks to simple interfaces, they can record their markers (object, image or QR Code) and associate them with different 3D models or documents. Applications, created with these editors, only support very light AR interactions, which consist in simply displaying digital content on the detected marker. Such application do not support feedback and automatic activity validation.

There are several open source technologies such as Artoolkit [34] or OpenCv for example, used to develop MaR-T and Robot Game. However, these open source and free technologies require advanced expertise in image processing.

Finally, there are several paying technologies, generally offering a free version, which allow developers to create MR applications, without being an expert in image recognition. The most popular is Vuforia [29] which offers good quality, stable and efficient services. Wikitude [35] and Kudan [36] are other alternatives.

\section{Conclusion and Discussion}

Through the analysis of eight Mixed Reality (MR) applications for teaching math in primary and secondary schools, we show that this technology offers several educational benefits such as cognitive offloading, captivating students' attention and making them 
learn while having fun. The experimentations, led by the authors of these applications, show that, even more than the AR augmentations (virtual information and object projected on real objects), it is the rich interactions, the custom feedback and help provided by the MR applications that have the highest impact on engagement and learning.

As we stand, the only technology capable of creating such rich MR interactions are paying technologies such as Vuforia, that requires solid programming skills. If we want MR to be accessible in schools, is it important to provide similar open-source technologies or MR editors that could allow teachers to create their own complex MR applications. In addition, the only way to develop the use of MR in schools is to provide applications that function with tablets since most schools are usually equipped with them and they are simple to set up. However, their use deprives children for using their hands at the same time. This constraint therefore needs to be taken into account when designing activities by clearly identifying when the children should be manipulating real objects and when they should pick up the tablet to get feedback or validate the exercises. Another method would be to design collaborative activities in which the children take turns in holding the tablet, while the other manipulates the objects. The experimentation also show that the MR applications should also function with markers teachers can easily print out on paper or cardboard. Another interesting perspective would be to help them create augmentations on material they already have in their class (e.g. cubes, globe) by using custom marker stickers.

\section{References}

1. D. Drascic and P. Milgram, "Perceptual issues in augmented reality," Stereoscopic displays and virtual reality systems III, 2653, pp. 123-134, 1996.

2. M. Wilson, "Six views of embodied cognition", Psychonomic bulletin \& review, 9(4), pp. 625-636, 2002.

3. H.-H. Liou et al., "The influences of the $2 \mathrm{D}$ image-based augmented reality and virtual reality on student learning", j-ets, 20(3), pp. 110-121, 2017.

4. P. Chandler and A. Tricot, "Mind Your Body", Edu. Psycho. Review, 27(3), pp. 365-370, 2015.

5. M. W. Alibali and M. J. Nathan, "Embodiment in mathematics teaching and learning: Evidence from learners' and teachers' gestures", Journal of the learning sciences, 21(2), pp. 247-286, 2012.

6. S. Kalenine et al., "The visual and visuo-haptic exploration of geometrical shapes increases their recognition in preschoolers", IJBD, 35(1), pp. 18-26, 2011.

7. C. Weng et al., "Mixed Reality in Science Education as a Learning Support: A Revitalized Science Book", JECR, 57(3), pp. 777-807, 2019.

8. C. E. Hughes et al., «Mixed reality in education, entertainment, and training », IEEE Comput. Graph. Appl., vol. 25, no 6, p. 24-30, 2005.

9. K.-H. Cheng, "Surveying students' conceptions of learning science by augmented reality and their scientific epistemic beliefs", Eurasia Journal of Mathematics, Science and Tech. Edu., 4(4), pp. 1147-1159, 2018.

10. H.-C. K. Lin et al., "Establishment and Usability Evaluation of an Interactive AR Learning System on Conservation of Fish", TOJET, 10(4), pp. 181-187, 2011. 
11. T. W. Watts et al., "What's past is prologue: Relations between early mathematics knowledge and high school achievement”, Edu. Resear., 43(7), pp. 352-360, 2014.

12. J. Sarama and D. H. Clements, Early childhood mathematics education research: Learning trajectories for young children. Routledge, 242 p, 2009.

13. P. Backlund and M.Hendrix, «Educational games-are they worth the effort? A literature survey of the effectiveness of serious games », VS-GAMES, 2013, p.1-8.

14. A. van der Stappen et al., "MathBuilder: A Collaborative AR Math Game for Elementary School Students", in proceedings of CHI PLAY, Spain, pp. 731-738, 2019.

15. R. Andrea et al., "Magic Boosed' an elementary school geometry textbook with marker-based augmented reality," Telkomnika, 17(3), pp. 1242-1249, 2019.

16. Y. Chen, "Effect of Mobile Augmented Reality on Learning Performance, Motivation, and Math Anxiety in a Math Course," Journal of Edu. Comp. Research, 57(7), pp. 1695-1722, 2019.

17. Z. Gecu-Parmaksiz and O. Delialioglu, “Augmented reality-based virtual manipulatives versus physical manipulatives for teaching geometric shapes to preschool children", BJET, 50(6), pp. 3376-3390, 2019.

18. G. Palaigeorgiou et al., Movable, resizable and dynamic number lines for fraction learning in a mixed reality environment, Springer Inter. Pub., , pp. 118-129, 2018.

19. Radu et al., "Discovering educational augmented reality math applications by prototyping with elementary-school teachers," IEEE VR, pp. 271-272, 2016.

20. Kazanidis et al., Dynamic interactive number lines for fraction learning in a mixed reality environment. in proceedings of the SEEDA, Greece, pp. 1-5, 2018.

21. S. Marichal et al., "CETA", in Proceedings of the MobileHCI, pp. 1-13, 2017.

22. C. Beşevli et al., "MaR-T" in Proceedings of the IDC, Austria, pp. 280-292, 2019.

23. R. Bujak et al., "A psychological perspective on augmented reality in the mathematics classroom", Comp. \& Edu, 68, pp. 536-544, 2013.

24. Radu, "Augmented reality in education: a meta-review and cross-media analysis", Personal and Ubi. Comp., 18(6), pp. 1533-1543, 2014.

25. H. Kaufmann, Geometry education with augmented reality. na, 2004.

26. Kotranza et al., "Real-time in-situ visual feedback of task performance in mixed environments for learning joint psychomotor-cognitive tasks", in Proceedings of ISMAR, U.S.A, pp. 125-134, 2009.

27. Birt et al., "Mobile mixed reality for experiential learning and simulation in medical and health sciences education", Information, 9(2), p. 31, 2018.

28. D. D. Süss et al., "Ergebnisbericht zur MIKE-Studie 2019," MIKE, p. 100, 2019.

29. "Vuforia library," 2020. https://library.vuforia.com/ (accessed Jul. 15, 2020).

30. M. Anastassova and al., "Ergonomics of augmented reality for learning: A review," Travail Humain, 70(2), pp. 97-125, 2007.

31. D. W. F. Van Krevelen and R. Poelman, "A survey of augmented reality technologies, applications and limitations," IJVR, 9(2), pp. 1-20, 2010.

32. Augment, 2020. https://www.augment.com/ (accessed Jun. 25, 2020).

33. Aurasma, 2020. https://www.aace.org/ (accessed Jul. 15, 2020).

34. ARToolKit, 2020. http://www.hitl.washington.edu/ (accessed Jun. 25, 2020).

35. Wikitude, 2020. https://www.wikitude.com/ (accessed Jul. 04, 2020).

36. Kudan Inc., 2020. https://www.kudan.io/ (accessed Jul. 04, 2020). 